\title{
Using Educational Technology to Enhance Creative and Critical Thinking Skills Through Open Ended Design Projects
}

\author{
John Tharakan ${ }^{1}$ \\ ${ }^{1}$ Department of Chemical Engineering, Howard University, Washington, DC 20059, USA \\ 1jtharakan@howard.edu
}

\begin{abstract}
Engineering students must develop creative and critical thinking skills to become real world problem solvers. Syllabi and curricula must demonstrate adequate preparation of the student to face real world challenges. In this paper, we report on incorporation of educational technology into freshman and senior core chemical engineering courses that facilitate rigorous development of creative and critical thinking skills. We elaborate on the incorporation of POLYMATH $®$ into these courses, and report on how the use of this technology, or equivalent, enables the straightforward inclusion of substantive openended design (OED) type projects. The courses each require year-level specific project-based deliverables that students work on in teams. The paper outlines key components of such exercises and articulates on the specifics of how these are assigned to students, the process by which the students work in collaborative groups and teams to develop the open-ended solution and discusses the rubric that students are provided so that they are aware of how the assessment and evaluation of their work will be conducted. The paper articulates on the components of the final report and presentations that the student's teams are expected to develop and deliver. The deliverable report requires the students to extract second order conclusions from the direct results from running the software. The technology rapidly produced results for engineering system models involving solution of coupled linear algebraic equations or coupled ordinary differential equations. Through these OED exercises, students were able to demonstrate their critical and creative thinking skills through focused reports that explored and articulated impacts of system variables and process parameters on system function.
\end{abstract}

Keywords: Creative thinking, critical thinking, open-ended design, educational technology

\section{Introduction}

As has been discussed in this journal before (Tharakan, 2018), engineering and engineering education (EE) have substantively evolved over the past century as technology and society have themselves been transformed through technological evolution and development. From EE's beginning as a formal discipline in the late $19^{\text {th }}$ and early $20^{\text {th }}$ century, academic educational thinking and policies have been developed and produced (Cheville, 2014), demonstrating changes in conceptualization and implementation of engineering education.

The Mann Report (1918), commissioned by three engineering societies, assumed the purpose of engineering was to improve industrial production. Engineering education's focus was pragmatic. Although taught in universities, engineering was not to be a purely academic discipline, and should emphasize both doing and knowing. Engineers clearly worked in the human realm and were more valuable in their practice if they could manage both human and material resources. However, EE policy at the time did not speak to creating problem solvers who would be able to take on the Grand Challenges in Engineering; nor did it speak to developing the critical and creative thinkers that would be needed to address the myriad Sustainable Development Goals that the United Nations Development Program has articulated as goals that must be met at the minimum to get to some measure of sustainability while ensuring that ALL people on the planet have access to clean 
water, clean air, renewable energy, safe and healthy food, quality healthcare, education and information so that they may be flourishing members of their communities. Wickenden et al (1930) at the time conceptualized engineering education to include science, mechanic arts, managerial skills and "building character"; the outcome of this education was to result in a man (at the time only men!) becoming an engineer, ".... a creator of machines and the interpreter of their human significance, ... and to organize industry for the more intelligent development of men."

EE shifted focus the pragmatic to the scientific by mid-century (Grinter, 1955), focusing more, academically speaking, on scientific bases of engineering. Understanding the science underlying the technology was a shift away from simple and direct application of science; hence, creative work and research began to occupy an elevated status.

With the founding of the National Academy of Engineering (NAE) under the umbrella of the National Academy of Sciences, tensions arose around whether engineers addressed only technical problems or was the charge broader and deeper, with global and social problems made part of engineer's focus (Walker et al, 1968).

The NAE report on Engineering Education and Practice in the United States (EEPUS, 1985) conceptualized a much broader function for engineers, a paradigm shift that placed engineers within the context of a larger economic and social system. It was clear from the NAE report that the core purpose of engineering was re-defined, becoming the creative element of a sociotechnological system, with the main charge of increasing prosperity and averting catastrophe! Engineers were no longer just solvers of narrow focused technical problems; instead engineers have an obligation to advance technological breakthroughs for the betterment of life, take leadership in the problem solving process and be able to focus on tackling societal problems.

What has been made clear is that engineers must be prepared to be able to take on the grand challenges in engineering before our world. To be that kind of a problem solver, engineering education has an obligation to ensure that creative and critical thinking skills are nurtured and developed as part of any engineering degree program.

\section{Critical Thinking}

What it means to be able to think critically has to be articulated for students. It is important that they understand what is involved in thinking critically about an issue. To think critically means to begin by asking questions to clarify the situation. It involves probing the assumptions that are inevitably made as part of the process of solving a problem. Critical thinking involves asking questions that probe reasons and evidence and ask go further to ask questions about perspectives and viewpoints, interrogating, for example, whether there are alternatives. To be a critical thinker also involves asking questions about the solutions that are developed and appear viable for the problems being tackled, probing issues about the implications and consequences of the solutions that are being proposed (Paul, 1992).

The skills that are essential to think critically include the ability to be analytical and break things down into parts, the ability to be logical and rational, reasoning things through to draw the proper and correct inferences and conclusions. One must be able to be discriminating, recognizing differences and similarities among things and/or situations, being able to distinguish groups and categories. The ability to apply standards is also a skill that is part of critical thinking, especially in engineering, where references, standards, benchmarks and specifications and codes are an integral part of every problem and solution. And of all of these skills must be undergirded by the skill of being able to research and seek out information, evidence, facts and knowledge by identifying relevant sources. Finally, being able to transform knowledge and apply it under changing and dynamic conditions is a hallmark skill all engineers in a world of constantly evolving technologies should have.

\section{Creative Thinking}

In order to be a complex problem solver under real world conditions, all engineers must, in addition to being critical thinkers, must be creative 
thinkers as well. To think creatively, students must be challenged to solve problems that are open ended and involve them in engaging their critical thinking skills as well as their technical knowledge of systems and system parameters and variables, to be able to develop solutions that interrogate system behaviour as a function of system parameters. There are never single correct solutions to open ended problems. Students can be formed into teams to work together to develop the solutions to the open ended problems and present them in the form of a report that includes discussion of the relevance, impact, validity, trends and implications of the solutions proposed. The most important question that students need to think about to exercise and develop these critical thinking skills is the "What if this happens...?" question, where the thing that is happening is relevant, predicted or unexpected changes in system parameters and variables.

For the well-defined student educational outcomes (Table 1) of any EE program to be achieved, it is clear that both creative thinking skills and critical thinking skills are essential components of the skill-sets that should be developed for the graduating engineer of today.

In this paper, we report on the use of educational technology in the form of a software math tool platform, POLYMATH®, and how the incorporation of this software package into a core senior level chemical engineering course enables the inclusion of open-ended design (OED) type projects that serve to develop creative and critical thinking skills in students in our program.

In this senior level core course on Chemical Reaction Engineering, three OED projects are assigned to the students to work in self-selected groups to develop the solutions for. In the Chemical Reaction Engineering course, these projects are senior level projects involving kinetics, mass transfer, heat transfer and reactor design, and require the simultaneous solution of ordinary differential equations. Now, although Differential Equations is a pre-requisite for the senior level course, and the students have the theoretical preparation to apply and solve differential equations analytically, the coupled differential equations encountered in the reaction kinetics and reactor design problems require numerical solutions. Developing the numerical solutions to the coupled differential equations, although not beyond the capabilities of the students, can be extremely time consuming and tedious. Here, we take advantage of educational technology in the form of the aforementioned POLYMATH ${ }^{\circledR}$ software package. The software package is usually included in the $\mathrm{CD}$ accompanying the textbook (Fogler,2016) that students purchase.

Table 1:Accreditation Board of Engineering and Technology mandated student educational outcomes for accredited engineering undergraduate degree programs

a) an ability to apply knowledge of mathematics, science, and engineering

b) an ability to design and conduct experiments, as well as to analyze and interpret data

c) an ability to design a system, component, or process to meet desired needs within realistic constraints such as economic, environmental, social, political, ethical, health and safety, manufacturability, and sustainability

d) an ability to function on multidisciplinary teams

e) an ability to identify, formulate, and solve engineering problems

f) an understanding of professional and ethical responsibility

g) an ability to communicate effectively

h) the broad education necessary to understand the impact of engineering solutions in a global, economic, environmental, and societal context

i) a recognition of the need for, and an ability to engage in life-long learning

j) a knowledge of contemporary issues

k) an ability to use the techniques, skills, and modern engineering tools necessary for engineering practice.

Referencing Table 1, the OED projects address several outcomes and such problems can be used effectively to assess student achievement of those outcomes. First and foremost, outcome (a) 
is addressed, as the development of the project report for the OED requires the application of scientific, mathematical and engineering knowledge. Application of this knowledge is demonstrated by the students by their conceptualizing a system, applying a fundamental principle to develop a model for the system including determining parameters that affect the behavior of the system, and outcome (e), identifying, formulating and solving the engineering problems presented in the OED project. The senior student teams are required to develop project reports for each of the three OED projects that they are assigned over the course of the semester. Student teams focus on addressing the deliverables expected from the OED. This written report addresses outcome $(\mathrm{g})$, the ability to communicate in writing effectively. For the third and final OED project, after students have received feedback from two rounds of OED project submissions, student teams also make oral presentations of their project reports, further addressing the communications outcome.

To develop their reports, the students must "run" their models under various scenarios of system parametric variation. This requires multiple solutions of systems of ordinary differential equations that are the mole balances for the reacting systems the senior students are investigating. Students are provided terminals on which copies POLYMATH ${ }^{\circledR}$ software have been installed or they are provided a CD from which to install the software on their own computers. Unfortunately, the POLYMATH® software package is not available for a Mac operating system, although students with PC laptops can download the POLYMATH® software for free as a Trial version that provides them with sufficient computational cycles to enable them to develop solutions for their OED problems. The class has always also had students who are familiar with alternative software to solve coupled ordinary differential equations such as MATLAB $®$ and some are even able to use their MS EXCEL ${ }^{\circledR}$ packages to develop the solutions.

Critically structuring the OED project, at both levels, to ensure that these outcomes are addressed is possible by clearly articulating the set of expectations and deliverables that the student

teams must work together to develop and submit, and present, in the case of the seniors

\section{Methods}

The senior course is the Chemical Reaction Engineering course, a core senior-level course in our BSChE program. In this course, students have three open-ended design projects that they must work on in groups. The first involves the straightforward modeling of a 2 -species predatorprey system, in this case an island with an infinite supply of grass for rabbits, who only have foxes as their predator. The assignment is shown in Figure 1.

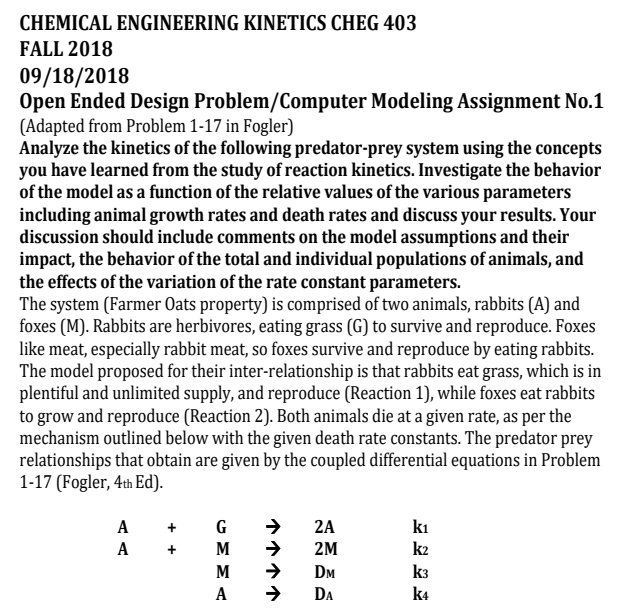

Use POLYMATH (or MACTHCAD if you so choose) and conduct "computer experiments" to see how the rabbit and fox populations vary with different values for the death and growth rates (kinetic constants). Conduct sets of computer experiments varying the parameters in a logical and related manner (for example, what if rabbits die four times faster then foxes?). Discuss the behavior of the mode and the results you obtain, specifically as they might pertain to any available real The deliverable for the assignment is the problem statement and set-up, a printout of your model equations, printouts of relevant results (graphical), and a maxim of 1-page (typed double spaced) discussing the results of your experiments and

DUE DATE: Tuesday, October $11^{\text {th }}, 2018$

Figure 1: $1^{\text {st }}$ Open Ended Assignment, Predator-Prey Model.

This simple system gets student's used to the idea of developing a model system of ordinary differential equations governing the variation in time of the populations of predators (foxes) and prey (rabbits) and then programming that system of equations into POLYMATH ${ }^{\circledR}$ and solving the system of equations while varying parameters, in this first case the birth and death rates of the rabbits and the foxes (Fogler, 2006).

The second open-ended project requires the student team to investigate the behavior of a inert membrane catalytic feed-side reactor 
(IMCFR) and comparing the IMCFR to a regular plug flow reactor (PFR). Student teams must develop the mole balance equations for the two reactor configurations, resulting in a pair of coupled differential equations based on the mole balances of the reactants and products, factoring in the selective mass transfer of one of the components across the membrane. The teams must investigate the behavior of both the reactors under varying conditions and parametric values, to determine what kinetic, mass transfer and process parameters most affect the behavior of the system, and how they affect that behavior. After developing the model equations, student teams then investigate, through the utilization of the POLYMATH ${ }^{\circledR}$ platform, how the variation in the different parameters affect the outputs from the model they developed. This OED project is shown in Figure 2 (Fogler, 2016).

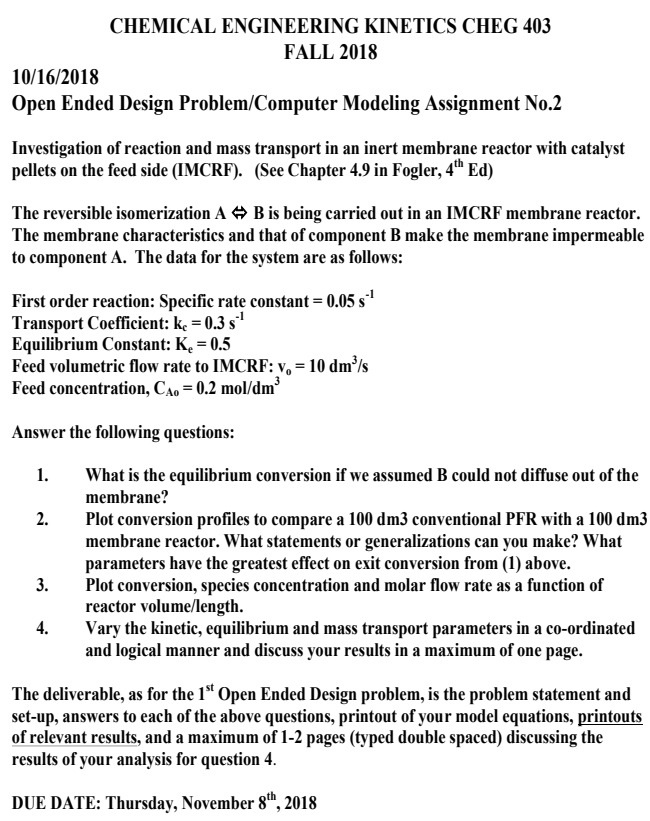

DUE DATE: Thursday, November $8^{\text {th }}, 2018$

Figure 2: $2^{\text {nd }}$ Open Ended Assignment: Analysis of the Performance of an Inert Membrane Catalytic Feed Reactor.

The third and final OED project for the senior students involves the investigation of a continuously stirred tank reactor (CSTR) in which an exothermic reaction is taking place and the reactor is a jacketed vessel with heat exchange occurring. This final OED project assignment is shown in Figure 3. In this project, the students work to develop the mole and energy balances for the continuous flow reacting system and then simultaneously solve the mole and energy balances in their model, while varying the various parameters that emerged as governing the behaviour of the model. These include the heat transfer coefficient, the rate constant, the inlet and outlet temperatures, the heat of reaction and other parameters and variables that the student teams can justify and articulate a clear case for varying in the process.

In this third and final project, the student teams develop a written final report as well as a formal presentation on the results of their modelling and investigation of the non-isothermal reacting system they were presented with. This third and final OED for the senior students provides the students a clear opportunity to demonstrate that they have indeed achieved the outcomes that were articulated earlier in this paper pertinent to this senior level core chemical engineering course.

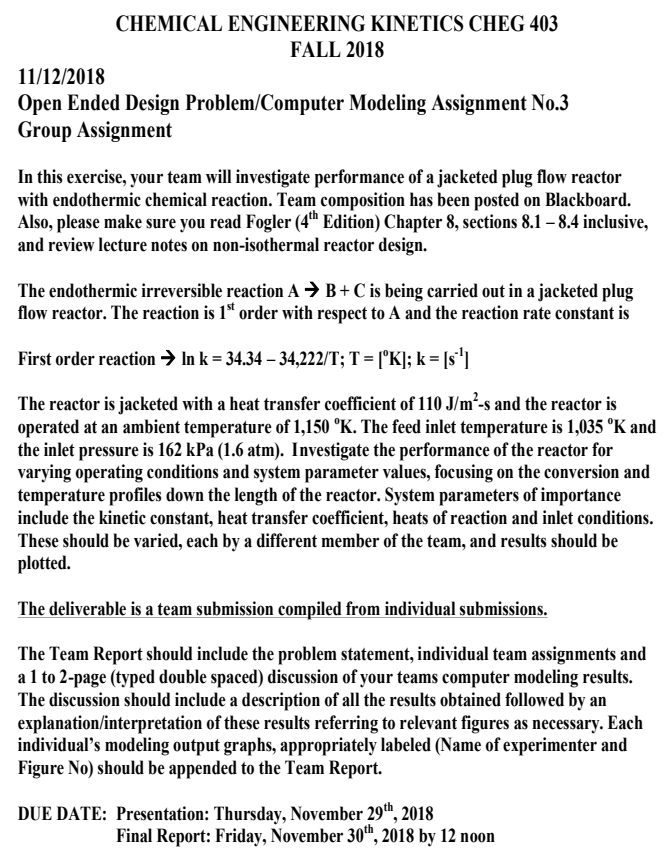

Figure 3: Third and final OED Project: Non-isothermal Continuously stirred tank reactor with heat exchange.

As part of the implementation of the OED assignments, the written reports are rigorously assessed to ensure that the student teams have developed the correct model equations, have selected process parameters of relevance, have varied these in a logical and critical manner, have 
presented the results of the model runs in a logical way with clearly labelled graphs, and have developed second-order conclusions from an analysis of their model results that can speak to the trends and patterns demonstrated by their models and analysis.

Students were organized into groups of three to four students. In the current iteration of the course, there were twenty-three students in the course, resulting in seven groups of 3 students each, with the remaining two students added to two groups, finally resulting in two groups of four students and five groups of three students. The students had to organize themselves and work together to produce the deliverable. Part of the reporting requirement included an Responsibility and Accountability statement that was required on the cover page, and which had to be signed by each student in the group.

In general the reports from the $1^{\text {st }}$ OED lack well-organized results that were clearly graphically presented, they tended to have poor analyses of the results, weak interpretations and conclusions, without much attention paid to trends and predictions that could be deduced from their results. The impact of the rigorous assessment and feedback provided to each student team is seen in the dramatic improvement in the quality of the $2^{\text {nd }}$ OED project. Reports. Here, it was generally found that the selection of parameters to vary, the range of their variation and the impacts of the variation were clearly articulated and presented. Second order results were discussed and trends and prediction from the model's performance was discussed and analysed. In the $3^{\text {rd }}$ OED project, this trend was further strengthened with the number of students doing well increasing to include all the team members. The final project is assessed both as a final project report and a final group presentation. The assessment rubric is shown in Figure 4 below.

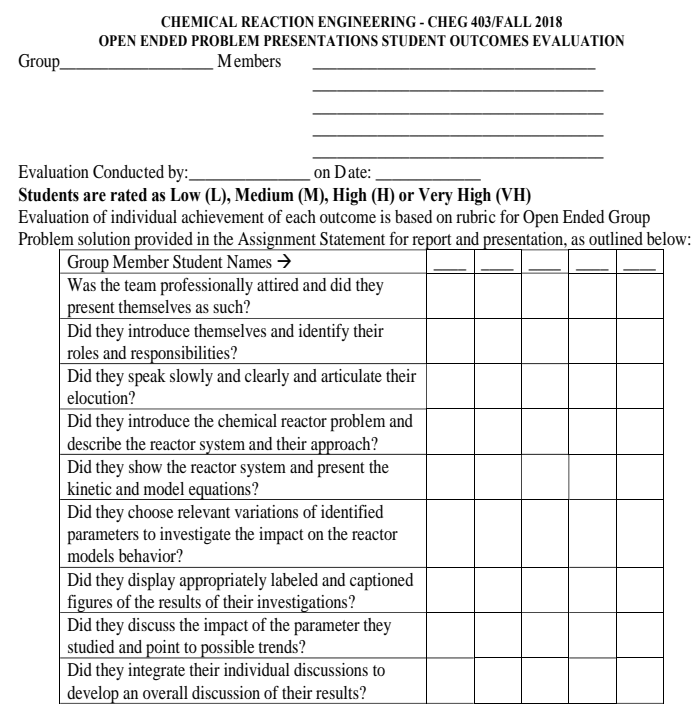

Figure 4: Assessment Rubric for Evaluation of Student Reports and Presentations.

When presented with the open-ended nature of the project assignments, the students have to exercise their creativity in choosing what range of parameters they use in the development of their solutions and in production of their final project report. And their critical thinking skills are exercised as they interpret and analyze the outputs from the computer model experiments they run and as they extract second order results from their analyses, showing how parametric variation affects system behavior and outcomes. It is insufficient for the student teams to present the direct results of the solutions of the model equations for several values of different parameters. As students are reminded, these are straightforward first-order results that come directly from the outputs of the model solutions, and, for a report to meet standards demonstrating analytical and critical thinking, second order results that need to be extracted from the direct outputs from the models solutions also need to be presented. Thus students cannot simply turn in outputs from their POLYMATH runs; they need to take these outputs, further analyze them to extract and develop second order model results, which must be included in their reports and their oral presentations.

The performance of the student teams on the OED project assignments was assessed at the end of the semester. The results are shown in Figure 5 
below. As can be seen from the data on student performance, the strategy of having three OED projects of increasing complexity through the semester provided a pathway for students to become more competent in their analysis and develop their critical and creative thinking skills. This, of course, depends on the student teams receiving substantive feedback and critique of the reports they generate as part of the OED project submissions. Each of the reports was rigorously reviewed and evaluated, and the whole student team participated in meetings with the professor to receive the feedback on their group report. This has clearly improved performance.

Feedback from the students indicated that they were very satisfied with this pedagogical approach. Although a quantitative assessment survey has not yet been conducted, the outcomes self-assessment that the student's undertake each semester for each course demonstrated that the students found the course was very important to their development of critical and creative thinking skills, improved greatly their ability to communicate both in writing and orally and enhanced their ability to work in groups and contribute to the development of a team-based deliverable in a competent and professional manner.

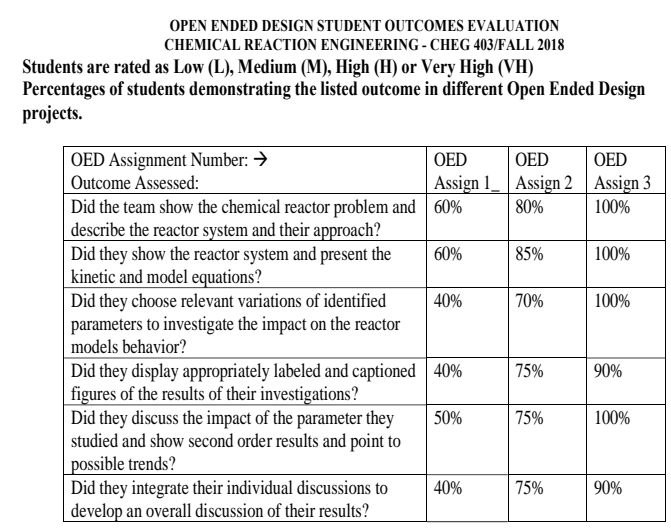

Figure 5: Student teams performance in the Open Ended Design Project report submission and demonstration of achievement of outcomes.

\section{Conclusions}

It is clear and obvious to all engineering educators that creative and critical thinking skills need to be developed in engineering students in order for them to be successful in today's rapidly transforming socio-technological environment. We have shown that incorporating an educational technology platform such as POLYMATH® facilitates and enhances students ability to be challenged with open-ended problems involving the solution of coupled ordinary differential equations. Using a series of OED team based projects, and providing rigorous assessment and feedback for the first two OED projects, results in the student teams developing outstanding and comprehensive reports involving critical and creative thinking to present a broad and open ended solution to the final project focused on the behavior of a non-isothermal reactor. From the student's presentations, it was clear that incorporating these OED type projects that students worked on in teams, clearly enhanced their analytical and communication skills enhancing their employability.

\section{Acknowledgement}

The author wishes to acknowledge the support of his students and colleagues at the department of Chemical Engineering at Howard University in discussing this pedagogical approach. The author further acknowledges the contribution of the Fulbright-Nehru program in facilitating and supporting the author's research and scholarship.

\section{References}

Accreditation Board for Engineering and Technology, (ABET) Criteria for Accrediting Engineering Programs 2008, Engineering Accreditation Commission: Baltimore.

Cheville, Alan, "Defining Engineering Education," Proc.

$121^{\text {st }}$ Amer.Soc.Engg.Educ.Ann.Conf., Indianapolis, IN, June 2014.

Clough, G.W.e.a., The Engineer of 2020: Visions of Engineering in the New Century, 2004, Washington, DC: National Academy Press.

EEPUS, 1985: Committee on the Education and Utilization of the Engineer, Engineering Education and Practice in the United States: Engineering in Society, Washington, DC: National Academy Press.

Davis, M., Defining "Engineer"- How to do It, and Why it Matters. Journal of Engineering Education, 1996. 85 (2).

Fogler, H.S., Elements of Chemical Reaction Engineering, $4^{\text {th }}$ Edition, Prentice-Hall, New York, 2006.

Froyd, J.E., P.C. Wankat, and K.A.q. Smith, Five Major Shifts in 100 Years of Engineering Education. Proceedings of the IEEE 2012, 100 (13): p. 1344-1360.

Lancioni, R. A. and Chandran, R. (2009) Managing knowledge in industrial markets: New dimensions and challenges, Industrial Marketing Management, 38(2), 148151

Mitcham, C. and E. Schatzberg, Defining Technology and the Engineering Sciences, in Philosophy of Technology and 
Engineering Sciences, A. Meijers, Editor. 2009, Elsevier: Amsterdam.

Paul, R.W. (1992) Critical Thinking, Foundation for Critical Thinking, Santa Rosa, CA

Tharakan, J., (2018)" Developing Creative and Critical Thinking Skills Through Open Ended Design Projects at the Freshman and Senior Level," J.Eng.Educ. Transformation, Jan 2018.

Walker, E.A., J.M. Pettit, and G.A. Hawkins, Goals of Engineering Education: Final Report of the Goals Committee, in Engineering Education, 1968. p. 367-446.

Wickenden, W.E. and H.P. Hammond, Report of the Investigation of Engineering Education 1923-1929, 1930, Society for the Promotion of Engineering Education: Pittsburgh, PA. 